\title{
HRD Role in Organizational Development (A Case of Corporate Thinking at ETISALAT, UAE)
}

\author{
Nadir Kolachi ${ }^{1} \&$ Obasi Akan $^{2}$ \\ ${ }^{1}$ Skyline University, UAE \\ ${ }^{2}$ North Carolina A\&T State University, USA \\ Correspondence: Nadir Kolachi, Skyline University, UAE. Tel: 971-56-264-2546. E-mail: \\ nadir.kolachi@gmail.com \\ Received: June 27, 2014 \\ Accepted: July 15, 2014 \\ Online Published: July 25, 2014 \\ doi:10.5539/ibr.v7n8p160 \\ URL: http://dx.doi.org/10.5539/ibr.v7n8p160
}

\begin{abstract}
The paper reports on the role of HRD towards the changing practices of OD in the companies. OD practitioners always utilize HRD processes to speed up the success based on the OD practices. The best corporate thinking is to lead company towards success with simplified models \& processes. This paper submits a basic approach of four steps that elaborate the role of HRD and justifies the practices of OD as required in modern companies. There are various processes that are used as company development but HRD; OD \& CMP are the dominant factors for companies' success. Organizations are not interested in evaluating and adopting complex processes but looking for simplified tactics to achieve the results as desired. This paper will describe the practical framework based on the four steps that are basic parameters of OD with required explanations of HRD roles. Top companies have maintained such strategic role in sequential way by putting organizational management as initial point that builds the strategic lines for organizational development. There are many things that keep changing the shape of an organization but HR \& OD remains same. The innovations in technology, the development of employees or organizational hierarchy depends on the trends of workforce. Workforce can put company into different shape in order to lead for success. This is the corporate approach that is linked with the practices of HRD \& OD in modern organizational times. All different specialized managers seek different opportunities in the modern practices. HR managers utilize the development opportunity from organizational management perspectives and this can be possible due to the combined activities of HRD \& OD in modern companies. This paper is mainly concerned to HRD role in OD that is termed as corporate thinking and evaluated on the success of ETISALAT.
\end{abstract}

Keywords: corporate thinking, HRD roles, OD practices, ETISALAT

\section{Introduction}

HRD role always keep changing based on the changing patterns of organizational activities to deal and manage the workforce. Different strategies keep coming towards HRD practices in order to manage employees who are having different styles, different exposure, varied background and most importantly ambitious driven approach for organizational productivity. This makes top hierarchy employees to innovate the sources that can add and have smooth organizational development in the current competitive world. This creates a high demand of responsible followership and leadership from the HRD heads. HRD role is to formulate all strategies that are connected to achieve organizational development activities. HR managers contribute towards organizational development in form of orienting, training, mentoring, updating, instilling ownership, motivating and creating good environment to maintain HR discipline from employers and employees respectively. This situation makes HR managers to take initiatives regarding organizational standards, organizational professionalism, organizational productivity and organizational longevity as widely mentioned in this paper. The proposed framework shows a sequential role in the development of an organization. HR managers do not see any reason of failure in the OD process but can be a problem if any of the parameter is ignored. This Framework is proposed to put sequential steps to achieve organizational success. This model comprises on four main parameters as HRD role in the beginning and then four other important factors as Organizational standards, professionalism, productivity and longevity. These factors are also further divided into three sub factors in each point. Generally, HR role in the organization is to identify the best talent and provide organization with best solutions. HR is 
always known as strategic partner because it supports in strategic \& diverse thinking at the workplace. Technically, HR's job is to make sure that diversity is implemented in each functional department. This makes everyone to contribute and come up with good idea to promote organization. Varied advantages are available in implementing workforce diversity in the organization. The purpose of encouraging diversity in different departments is to take benefit of varied backgrounds, exposure, knowledge, skills, experience and tactical approach to problem solving. This role can help in development based on the organizational requirement of learning and having diversified participation. HR plays a role of setting strategic directions and suggests evaluating the diversity programs to equip organization with the varied exposure. The next step is highly demanded by HR development activities. HR actively participates and innovate the possible training programs to evaluate the competency level of employees. HR cooperates with higher authority to identify the competitive skills required for competing the crucial tasks of an organization. Competency is the ability of an employee that is much required by competitive companies while competitiveness is the plan of identifying required expertise for the betterment of the company. HRD plays a role in achieving competency through customized employee training and maintain employee branding activities in order to achieve competitiveness as desired by an organization. The most identified role of HRD in OD process is service delivery \& maintenance. Service delivery is the strategy of answering all concerns of employees. HR maintains an open door policy to keep employees updated \& corrected. HR orientations are also part of service delivery. HR maintains such service through providing the required employee cards, providing employee handbook, orienting employees with crucial tasks and important information. HR service delivery is important but to maintain it as an urgent task for the modern companies. OD is required process that is always achieved through such delivery and maintenance in particular. This technical role of HR is PD process that coordinates on the profitability. HR keeps rewards of what happened last year and what are they going to achieve in forthcoming years. HRD's accurate training, service delivery, working competiveness and identifying diversified backgrounds will enable organizations to make to the list of top competitors.

\section{Literature Review}

ETISALAT is a leading telecommunications corporation catering to consumers, businesses, international telecommunication companies, content providers and mobile operators. Headquartered in Abu Dhabi, UAE, ETISALAT is the largest operator in the Middle East and Africa regions. ETISALAT has one of the highest credit ratings for a telecommunications corporation in many countries. ETISALAT operates in 18 countries across Asia, the Middle East and Africa, a coverage area which reaches more than two billion people. To date, the group's global subscriber base exceeds over 140 million subscribers through mobile and Landline voice and data services (www.ETISALAT.ae). Through ETISALAT's major investment in Thuraya Telecommunications Company, a leading international mobile satellite service provider, the corporation's connectivity coverage reaches the majority of the entire planet. The corporation offers a variety of hi-tech complimentary services to the telecommunications industry including managerial and technical training, SIM card manufacturing, payment solutions, clearing house services, peering, voice and data transit, and submarine and land cable services (www.ETISALAT.ae). The Human resources department's objectives are to attract recruit and retain qualified staff with great emphasis on UAE Nationals. Also, to maintain internal equity of job grades and ensure external competitiveness of our salaries \& benefits. Upgrading, training and developing employees to cope with international standards are very important aspect at ETISALAT. HR also aims to create healthy working environment by establishing the sense of belonging, teamwork and respectful treatment. ETISALAT needs workers with different skills and perspectives, values and attitudes, resulting in different recruitment and selection strategies. The focus is on the employment of 'smart' and resilient people who are innovative and curious and have the ability to work in teams or groups with the aim of sharing expertise. In other words, ETISALAT selects the "right" people to be placed in the "right" place (www.ETISALAT.ae). Good organizations have adopted a trend of strategic collaboration between HRD \& OD in the organizational achievement patterns. This pattern like inducting good people, motivating and building their intellectual capability for the purpose of supporting organizational development perspectives is good step and ETISALAT maintains it with high level since many years. HRD role in OD is required to show high professionalism. HR role is always successful if shown in professional way. It has its own way with disciplined approach. Most research emphasizes the importance of professionalization of HRM functions i-e that it has become a profession in its own right (Wiley, 1998; Martin \& Woldring, 2001; Wooten, 2001). HR is the most professional job and humanly if shown in real professional way otherwise employees start considering it as inhuman. HRM is accused of redesigning the meaning of work and the organization employee's relationship in order to make existing and intolerable practice acceptable, some authors regard HR as sum of total dehumanizing practices (Towny, 1993), the suppression of resistance \& confrontation (Sennette, 1998). HRD has most important role in human 
development. HRD plans training for employees' development. Training is an active parameter to build employees. As said by Gode (1993) the most effective way to invest in HR is to provide workers with training to enable them to provide the performance (Gode, 1993). There are various professions and occupations but there is also continuous growth in the profession in USA, UK, Asia and many other places. This has been an increase in the proportion of professionals in the UK (Gold, 2007) and business schools (Bennis, 2005). The difference is well identified in the definition given by Cheetham and Chivers 2005. Such concepts, definitions and growth in professionals have increased the rigorous need of disciplined professionalism in the profession. HR is the only field that has focused to perform in most professional way. Technically, Professional people are the people who know their job and identify the required deliverables for the company. Larson (1977) has said that professional advancement is clearly based on the fact that there is clearly identifiable knowledge base that can be controlled but equal the professional be able to apply what they have learned (Larson, 1977)

\section{HRD Role in OD Practices (A Proposed Framework)}

Following are the sequential parameters that are proposed to evaluate the role of HRD that is required in OD process. First maintains standards, second encourages professionalism, third enhances productivity and fourth will ensure longevity of an organization. All four steps are the required parameters for HRD role towards OD process that can be practiced by good companies.

Table 1. HRD roles in OD practices (a proposed framework)

\begin{tabular}{|c|c|c|c|}
\hline $\begin{array}{l}\text { Strategic \& Diverse thinking } \\
\text { Competency \& Competitiveness }\end{array}$ & HRD roles in OD practices & \multicolumn{2}{|c|}{$\begin{array}{c}\text { Service delivery \& Maintenance } \\
\text { Profitable results \& long term survival }\end{array}$} \\
\hline$\underline{\text { Organizational Standards }}$ & Organizational Professionalism & Organizational Productivity & Organizational Longevity \\
\hline - Rigorous recruitment & - $\quad$ PD \& opportunities & - $\quad$ Set realistic goals & - $\quad$ ICD \\
\hline - $\quad$ Encourage diversity & Develop PD programs & Put HR to initiate & ITD \\
\hline - Improve HR services & - Deliver PD programs & HR communication & HRD \& D \\
\hline
\end{tabular}

\subsection{Organizational Standards}

- $\quad$ Rigorous Recruitment

- Encourage Diversity

- Improve HR services

Most of the companies claim that they have very good recruitment standards but still failed to either retain people or achieved organizational goals. This is tragedy if you invested much on recruitment but still failed to achieve desired results. This may happen due to the lack of rigorous recruitment standards or might have compromised on any of the point in the process. Rigorous recruitment is the systematic, a decided approach \& standardized criteria that is set by the company. Once the culture is set then need to implement and maintain but according to set criteria otherwise everything will be spoiled and become the cause of losing the set goals. Rigorous recruitment is known to the people who themselves have gone through such processes. Quality HR managers always maintain the rigorous process of hiring. If any company can control anything, they need to control an entry of employees to the company. HR role is important in inducting the right people. Right \& rigorous process of recruitment will have a high impact on results. The next role of HR in organizational structure is to enhance the diversity. The ultimate purpose of any organization is to move to progressive directions and that is possible through a collaborative role of HR especially in enhancing \& encouraging diversity. This thing has given more advantages to modern companies. These standards are all fixed that maintains the employee branding, employee relationship, employee communication and employee diversity. The final point after diversity is an important job of HR that is HR services in the company. HR service is an answer to all concerns of employees in most proper manner that does not lose anything from employer or employees. This is same as service delivery but service is more collaboration at all concerned departments. This research has observed few examples of corporate failures due to the ignorance of set standards. The only difference between successful and unsuccessful company is to follow the set standards. There has not been any other issue except in implementing the required standards set in the company. All companies do have good \& defined standards but success can only come if they are followed as planned otherwise failure is sure. This factor is important for organizational development and HR roles in collaboration to achieve it. 


\subsection{Organizational Professionalism}

- $\quad$ Professional Development \& Opportunities

- Develop professional development programs

- Delivery of Professional Development programs

HR role has always been an important in employees' professional development. This is the first step of professionalism in professional companies. HR maintains it through training processes in the company. Professional development is a process of making employees more disciplined, logical, responsible and accountable towards their task activities. Such activities if performed professionally have many opportunities. Professional HR development is essential in providing professional training. Few professional organizations have maintained utmost professional behavior and enticed many customers. This creates many opportunities for companies in order to maintain an image of the company. HR role in professional development program is an innovation in corporate success. HR should formulate programs like collaborative team sessions, human resource leadership sessions, loyalty forums, organizational ownership sessions, employee Employer interactions and technology related training for effective workflow automation in whole organization. Such programs can be best source for organizational development. All good companies implement such terms \& innovate further terms to be in the successful list of successful companies. HRD role is to innovate and maintain such sessions to equip employees for the development of organizations. HR managers in their context are also known as creative managers with reference to development of employees and organization in particular. The next factor is very crucial that demands an accurate implementation of the planned development programs in most proper manner and professional delivery. Employers want to see the benefits of all such programs to achieve the results of the company. Top US \& Japanese companies have high level professional program with highest professional approach to achieve the professionalism. The whole kudos goes to HR managers who maintain the professionalism and implement the preferred programs to the entire criteria of the company. This way organizational development process can be in successful way.

\subsection{Organizational Productivity}

- $\quad$ Set realistic goals

- $\quad$ Put HR to initiate

- HR communication

Organizational productivity is the result of planned goals and its achievement. Goals can be achieved if all departmental planning is in collaborative role among each other. HR role is to align people in a systematic way as they could contribute in achieving the productivity. Organizational productivity is possible if goals are set in most realistic way. Setting realistic goals are the goals that are achievable according to current constraints of the company. Companies cannot unnecessarily set high goals that are not possible. HRD role in setting realistic goals is to present complete evaluation of employees, then evaluate complete resources available in the company and then decide what is possible. Goals are set that are possible and have confidence in employees' cooperation. If employees cooperate and show interest in highest motivational level then goals can be achieved in real time. This is the main reason where HR is put in the decision to initiate the corporate activity and show complete plan of goals, employee expertise, and collaboration from other departments and due support form top hierarchy of the company. Few companies have faced serious complications due to their irrational goals setting. They set very good goals but they lack the manpower to achieve it. It is not important that some companies can set goals but knowing this expertise of the employees will be the best option to achieve the good goals. This whole process of setting goals \& putting HR into action is the prime activity of organizational development at modern companies. This is further implemented through a proper communication to the employees. HR communication is always used where ever a change process is required. People listen if they are listened but may resist if imposed without justification \& education. This is usual organizational development practice at various modern companies and has been in practice since two decades. This is only successful if HR role is understood as required.

\subsection{Organizational Longevity}

- ICD (intellectual capital development)

- $\quad$ ITD (Information technology development)

- $\quad$ HRD \& D (Human resource development \& Division)

Organizational longevity is the strategy that ensures the long term survival of the company even in the stiff competitive environment. This is the development process that all companies want to adopt but based on some 
tough criteria. HR role is at peak in this factor. HR role is always to build employees, build human capital that will help in building intellectual capital that is required by the company. Building intellectual capital means investing too much in the skills of employees, equipping employees with best tactical and technical skills. Few things are always existing in the good companies. Investment in technology \& intellectual capital is always remained productive. This is usually present at Japanese companies as they offer long term employment but equally available at other top US companies as well. Companies are aware about the benefits of IC \& ITD to survive in the competitive edge. Above two ICD \& ITD are possible if organization invest more in HR development \& diversity. Some good companies train the HRD department and then transform to other employees. This factor is essential and productive if ICD \& ITD are properly aligned in HRD. This may depend on corporate leadership that ensures to adopt all and even corporate tasks to complete with others. Most of the companies that are successful today are only successful because they have achieved tremendous response of employee interest in the investment of ICD and also facilitated employees with flexible Technology. This role of HRD made it successful to implement Organizational development practice at good companies.

All above sections are interdisciplinary; organizations may face serious dents if they miss any of the above. It is advised and mix decision to properly align, follow and adjust with the above points. Good companies have so for achieved success based on the accountable followership related to all four points.

\section{HRD Role in OD Practices (Application on ETISALAT)}

\subsection{Application on the Success of ETISALAT}

ETISALAT has a tremendous contribution in UAE. This company provides best service, time based delivery and accurate customer service since many years. Few competitors exist in the market but did not do anything against the successful activities of ETISALAT in many domains. ETISALAT maintained its highest level and got permanent position in customer minds. This research has evaluated the proposed framework on ETISALAT and found that the company has achieved most of the factors mentioned in the research. ETISALAT has a vision of continuous service and high volume customer database. This company has set high standards and achieved them with best system of hiring in the company. ETISALAT has a rigorous hiring system that takes many days for evaluating candidates and select the best who could be an asset for the company. It has maintained a diversified workforce in different departments and branches around UAE. ETISALAT has a motto of maintaining standards with full cooperation of employees and gaining best service to employees as well. ETISALAT is among top companies in the world that has a training academy that transforms and trains the staff. ETISALAT has a very innovative program for employees' professional development at all levels. They innovate the program, evaluate \& identify good trainers to deliver the best in all departments. ETISALAT also maintains the feedback to check if the program was successful and made a difference in work change. They make sure that professional development program had done due contribution as planned by the company. HR department of ETISALAT always keep maintaining the types of training, forums or short courses for employees. This makes the company to achieve all required processes of organizational development. The next is organizational productivity that comes at ETISALAT after professional development is complete. ETISALAT is very particular about setting goals and they highly use HRD plans to design strategies to achieve them. HR contributes to align the people and achieve the productivity as required by the company. They always put HR first but collaborate actively with other departments as well. The last point is company longevity. ETISALAT has proved the best one in achieving the last one regarding long term survival. ETISALAT has initiated lots of programs to contribute in this country (UAE). It has started programs that can build human capital and develop intellectual capital. They always maintain the behavior of employee entry based on different nationalities and local in particular. They want to create source to train local to contribute in order to develop intellectual capital for the purpose of country development. They have planned few years and guided HR to formulate the strategies to develop UAE intellectual capital in Telecom Sector. ETISALAT has also collaborated with other entities around the world for the purpose of moving the workforce with local to enhance exposure of ETISALAT employees and enhance the intellectual capital development programs. Such initiatives of building intellectual capital are much appreciated by the Government entities as well since many years. ETISALAT has also formulated many tactical innovations to share in the forthcoming EXPO 2020. ETISALAT plans to induct many people but special purpose for such building an intellectual capital in UAE. This always shows that ETISALAT has maintained most disciplined order of utilizing the proposed formalities in this research. This research has termed it as corporate thinking of ETISALAT in UAE.

\subsection{Application on the Challenges for ETISALAT}

Since there are many opportunities at ETISALAT but few challenges may also be there at the company. 
Company can adopt HRD to avoid the challenges of HRD at HR division. This is controlled by inducting diversity management at various departments. Company works on employee branding \& planning something good for work balance life programs. General knowledge versus field of specialization can also be worked more to maintain similar skills at many first line levels. ETISALAT avoids any HR challenges by offering good training to make employees as an ambitious driven workforce. This has proved and made managers to show responsible leadership.

\section{Research Design \& Approach}

The research in business administration especially at MBA program is not much focused as it should be. The technical research papers may help teachers to explore the empiricism of dimensions but research of case based approach can cater the realistic need of business administration. Comparing research journals with case research journals have huge gap. Though, some journals have case study section but very minute in number. The argument here is to focus on case study research in business administration. The paper is case based approach and has explored the corporate thinking to evaluate practical discussion of the topic that will enhance the practical approach of students, faculty and other business professionals. This case study is particularly designed with qualitative approach based on practical dimension of corporate thinking of ETISALAT (UAE). Though this case study covers many objectives as HRD role, OD process and corporate thinking but the proposed framework (HRD role in OD process) is highly explored, applied, explained and justified with its application on ETISALAT. The simple approach of qualitative case study was followed that covered various visits to ETISALAT (Head office), ETISALAT (Branch offices), ETISALAT training (ETISALAT academy), Corporate customers, individuals, service centers and also evaluated new packages including elife etc. The ultimate purpose was to evaluate corporate thinking and apply the proposed framework (HRD role in OD process) and list down the guidelines for business students to enhance their capability in understanding case and build an exposure to apply on different companies in future.

\section{Case Findings \& Recommendations}

ETISALAT is very successful company and maintaining the Corporate thinking with required standards as planned in mission \& vision statements. There are many areas that are improved at ETISALAT but still few can be explored more to beat many potential competitors ahead.

- Working on corporate culture at all levels.

- Top management should initiate more training for all to understand the commitment at all levels. More long term process should be planned

- $\quad$ ETISALAT needs to develop more corporate curriculum to train tactical staff.

This corporate case study has found that ETISALAT is one of the leading Telecom Company that is using HRD role in most productive way and utilize the OD practices in accordance with mission \& vision of the company. This case has also found that companies can take benefits of the proposed framework and benchmark the progress of ETISALAT with special reference to its HRD role \& OD practices in dealing with colleagues \& customers. The sequential steps in collaboration with HRD division will be much better for the smooth conduct of company operations. Corporations are at stake if they don't invest in achieving organizational standards to be in the market for longer time. ETISALAT is comparatively better than many companies in utilizing the sequential steps of the proposed framework in this research.

\section{Questions for Discussion}

Following are brief questions for faculty and students. The questions are designed in order to have an accurate understanding of ETISALAT's corporate thinking. It is advised that students and faculty must be familiar with the company, its website and its success stories of few years. Such familiarity will help faculty to discuss the case in most proper manner during the practical classes. These case questions will also help faculty to compare with other telecom companies.

- What is the corporate thinking? How did ETISALAT adopt it?

- What is the role of HRD in OD process at ETISALAT?

- Has ETISALAT achieved whole framework (HRD role in OD process) or still in process of achieving it?

- What are the obstacles of using proposed framework at ETISALAT?

- What are the competitive advantages of using proposed framework in modern age? 


\section{Future Utilization}

The purpose of Framework is to evaluate the corporate thinking of ETISALAT company in this research but can be used and applied on any other company may it be telecom, manufacturing, airline, education, government and any other domain. The proposed framework is general in approach and can be beneficial for many companies. There are very few frameworks \& cases on HRD roles in OD processes. Students \& Faculty of Business administration require such frameworks that may equip professionals with accurate understanding and can enhance their practical exposure of HRD role in OD process.

\section{Conclusion}

This concludes that Corporate thinking is the process of HRD role and OD practices in modern companies. Corporate thinking is initiated to achieve rational objectives and maintain the planned standards of the company. Corporate thinking is the way to evaluate the planned standards and formulate strategies to achieve them as per the professional criteria of HRD in the company. This research has proposed a Corporate thinking model for modern companies to be in the competitive race but at good position. The proposed corporate thinking framework will make companies to be better than competitors. This research has applied the proposed framework on the successful company (ETISALAT) in UAE. UAE is the place of mushroom companies of different sectors but still few companies are struggling to be good in some sectors. The proposed framework will enable companies not only in UAE but also in the rest part of the world. The idea of proposing such corporate thinking framework is to guide and present something sequential for modern companies. The framework is only applied on ETISALAT in this case research but can be positively applied and evaluated on other companies from any domain. This framework will best be applied in reference to HRD \& OD practices of modern companies. Not a single company can survive without the due contribution of HRD and sequential OD process in today's age. Whenever companies look for some special models or frameworks that can help them in dealing customers, motivating employees, making employees professional, making employees to achieve desired goals, coordinating with suppliers, stand by customers and standing against competitors in order to utilize the set standards of the company in particular. ETISALAT has achieved that all and still heading towards achieving more in coming years.

\section{References}

Bennis. (2005). How business schools lost their way (HBS).

Cheetham. (2005). Profession, competence \& informal learning.

ETISALAT Directory. (2013). Emirates Telecommunication.

ETISALAT handbook (intranet).

Gode. (1993). Cademos de Gestapo, Lisbon.

Gold. (2007). Continuing professional development, Management learning.

http://ETISALAT.com/en/ir/corporateinfo/overview.jsp

http://web2.ETISALAT.ae/eportal/en/corporate/history.html

http://www.itp.net/591265-ETISALAT-delivers-on-growth-potential

Larson. (1977). The rise of professionalism (A sociological analysis).

Martin. (2001). Ready for the mantle. International Journal of HRM, 243-255.

Sennette. (1998). The corrosion of character, Norton \& company.

Towney. (1993). Power/knowledge and its relevance to HRM, AOMR.

Welcome to ETISALAT (n.d.). Retrieved on March, 2013 from http://ETISALAT.ae/

Wiley. (1998). Reexamining perceived ethical issues \& ethical role among employment managers. Journal of Business ethics.

Wooten. (2001). Ethical dilemma in HRM. HRM review, 159-175. 


\section{Appendix}

Appendix 1. Acronyms used in this paper.

- $\quad$ OD (Organizational Development)

- $\quad H R D \&$ D (HRD and HR Division)

- HRD (Human Resource Development)

- ICD (Intellectual Capital Development)

- $\quad$ CMP (Changing Management practices)

- ITD (Information Technology Development)

\section{Copyrights}

Copyright for this article is retained by the author(s), with first publication rights granted to the journal.

This is an open-access article distributed under the terms and conditions of the Creative Commons Attribution license (http://creativecommons.org/licenses/by/3.0/). 